\title{
Influence of Metal Pipes in the Environment on Designing the Underground Electrical Installations
}

\author{
Igor S. Bjelić \\ The National Archaeological Institute of Serbia, Belgrade, Serbia \\ Email: igor_bjelic@yahoo.com \\ Filip N. Marković \\ Faculty of Technical Sciences, Kosovska Mitrovica, Serbia \\ Email: ridjikm@gmail.com \\ Nenad A. Marković \\ Higher Technical School of Professional Studies Urosevac, in Leposavic, Serbia \\ Email: nen.mark74@yahoo.com \\ Slobodan N. Bjelić \\ Faculty of Technical Sciences, Kosovska Mitrovica, Serbia \\ Email: slobodanbjelic49@yahoo.com
}

Received: 15 March 2020; Accepted: 20 August 2020; Published: 08 December 2020

\begin{abstract}
Underground installations are networks of metal pipes and cables in space at a certain distance from the ground surface. Insulating layers of metal pipes of underground installations (gas, plumbing, electrical...) do not provide their full protection against corrosion and breakdowns. In urban areas, wandering currents (electric rail or earthing of power plants) repeatedly increase failures in underground installations in the environment. That is why a certain kind of protection is foreseen for the protection of metal pipes of underground installations against corrosion and destruction from wandering currents. However, until today there is no universal method for calculating the parameters of stationary and quasi-stationary electric fields of wandering currents and a general solution for arbitrary configuration, but it is possible to form a model algorithm for controlling the state and failures of insulation of underground electrical installations. Solutions for wandering currents could be determined by the criterion of similarity to transient currents on power lines. In the paper, in program MATLAB Simulink a simulation for the correction of wandering currents using foreign grounding has been performed on certain parts of underground installations. It has been shown that the solution of the task is possible with help of the model-algorythm which allows a determinaitn of the power on isolation layer of the cable sheat, and with simulation of the different versions of schedule of protective equipment, their optimal schedule could be determined.
\end{abstract}

Index Terms: Underground installations, standards, grounding, protection

\section{Introduction}

Designing a system of underground electrical installations is actually the planning and selection of elements parameters of its structure in relation to the given functions and technical management of that system [1,2].

Direct currents create electro-chemical processes, and corrosion of reinforcement parts of concrete structures through which electricity flows, damages underground pipes, tanks, grounding. The effect of alternating current on the conductive structure of the underground installation and grounded contours is analyzed by adding a current source of a given frequency to the model for simulating the transient process [3].

Atmospheric discharges and electrical sources create wandering currents between metal elements in the earth. Solutions for wandering currents can be determined by the criterion of similarity to transient currents on power lines. Discharge is an electromagnetic high-frequency phenomenon whose effects are surges and surges, resulting from rapid changes in the potential gradient near the ground, and the direct impact of the discharge leader into conductors or parts 
of electrical equipment $[4,5]$.

In addition to technical, economic criteria are also important when planning underground installations. Solution algorithms are based on artificial intelligence and simulation of graphical tests but are unavailable [6].

The standards that must be followed regarding the parameters of installation elements, atmospheric discharges and protective grounding are:

1. EN 50162-Wandering current protectionand IEC 50364-Requirements for earthing systems in TN and TT networks (mutual ground resistance is determined by IEC 60364-5-54-2012/A11 and EN 62561-2-013) [7],

2. IEC 50364-Grounding as protection against electric shock and lightning current (hazardous touch of inactive parts) [7].

New methods are needed to calculate parameters of installation elements and protective earthing. The structure of underground power grids makes it difficult to apply only analytical methods and, due to modeling of variants of the solution, together with the algorithm, into the packagepsbramblecurrent.mdl [8], presents a part of surroundings. Similar goes for other underground installations with metal pipes. In this paper, it is shown that solutions could be found by applying the method based on Thompson's telegraph equations, which were applied for calculation of processes on cables and implemented in the MATLAB software package.

This paper is organized as follows: Section 2 provides an overview of related works in the field of underground installations Section 3 describes the protection of underground installations from discharge, as well as the choice of schedule and type of protective grounding. Section 4 gives the parameters of underground installations (distributed, concentrated) as well as the types of grounding conductors for protection against atmospheric discharges. Section 5 presents the detection of faults in an underground installation that are eliminated using conventional methods. Simulation results of wandering currents from foreign grounding on certain parts of the cable network and gas installations are given in Section 6. Finally, some concluding considerations are presented in Section 7.

\section{Related Works}

Being involved in the design of underground electrical installations and the appearance of wandering currents that increase faults in them is not a new phenomenon. Many studies have been conducted on this topic and a number of papers have addressed this issue [6,9].

The problems of the flow of current through the earth have been known since 1880, when Thomas Edison developed systems of transmission of direct current for the supply of electric lighting.

There are many sources of wandering currents in the country, and these currents vary in origin and time. B. Ilić and others [10] and M. Tanasković and others [11] in their work they state that problems caused by wandering currents are related to corrosion of underground metal installations. That is why a certain type of protection is foreseen for the protection of metal pipes of underground installations against corrosion and destruction from wandering currents. This protection against stray currents and the resulting atmospheric discharges are performed according to technical norms and standards [7,12].

Atmospheric discharges were explored in the 1980s by Magono [13] who suggested that this problem be approached from a computer side, because he came to the conclusion that much simpler and faster solutions were obtained.

According to B. Jovanović and others [3] grounding plays a very important role in the design of underground installations. Natural elements are used for metal cable lining, pipes, reinforced concrete foundations, etc. If the earth voltages are greater than the order of magnitude of $5 \mathrm{kV}$, certain protective measures must be provided, B. Jovanović and others concluded at the end of their presentation.

\section{Protection of Underground Installations}

The choice of cable protection characteristics requires a calculation of the field of wandering currents to bring the jacket to zero potential and limit the voltage changes to the permitted levels [14]. Underground installations are networks of metal pipes and cables in space $x<0$, on distance $m$ from the surface. Potentials $\varphi=\varphi(x, y, z)$ which create wandering currents define conductances $\sigma_{i=1,2,3,4}$ (1-ground surface, 2-metal pipes, 3-isolation cover and 4-layer of soil arounf the cable/pipe). The final dimensions are of the order: diameters $(\mathrm{cm})$, lengths $(\mathrm{km})$ sheath thickness $(\mathrm{mm})$, isolation $(\mu \mathrm{m})$. These scales create difficulties in the field models of wandering currents. A theoretical solution exists for long lines of diameter $d$ on depth $m$, but not for finite size lines. Potentials $\varphi=\varphi(x, y, z)$ and voltages $v=\varphi_{i}-\varphi_{j}$ are determined from the Laplace equations [6].

The choice of layout and type of protective earthing is done according to IEC standards [7] and for environmental reasons. The basic objectives of earthing and equipotential bonding in an underground installation are: 
- the safety and limitation of the touch voltage and the length of the contours through which wandering currents circulate,

- EMF elimination of potential difference (short circuit of all ground loops is not possible) (safety is ensured by an equipotential "cage", EN 50162).

Grounding for lightning protection, low voltage overvoltage, TT systems, and step and touch voltage earthing are combined to equalize the potential. Grounding conductors are: rod, tube, strip, wire, plate and embedded in the foundation as metal (in concrete cavities, with resistance to $10 \Omega$ ).

Table 1 gives the values of the specific resistance of the soil in which the grounding conductor is installed [7].

Table 1. Values of specific soil resistance in which a grounding device is installed

\begin{tabular}{|l|l|}
\hline Country type & Middle value $\rho(\Omega \mathrm{m})$ \\
\hline Humus & 30 \\
\hline Arable, clay & 100 \\
\hline Wet sand & 200 to 300 \\
\hline Dry stone soil & 30000 to 10000 \\
\hline Concrete foundations & 100 to 150 \\
\hline $\begin{array}{l}\text { The mean } \rho \text { depends on the type of soil, heat, moisture, depth at } \\
\text { which the grounding is, as well as the season. }\end{array}$ \\
\hline
\end{tabular}

Atmospheric overvoltages and dangerous wandering currents occur for two reasons (IEC 62 305-1) [12]:

- due to rapid changes in the potential gradient near the ground,

- due to the direct impact of the discharge leader into conductors or parts of electrical equipment [15].

The effects of lightning current are due to the energy of "the shock wave" [3] which form is determined in (IEC 62 305-1) [12].

The levels of vulnerability are, Table 2 :

- big: the first power surge $I=200(150) \mathrm{kA}, T_{1} / T_{2}=10 / 350 \mu$ s and the subsequent electric shock $I=50(37) \mathrm{kA}$, $T_{1} / T_{2}=0,25 / 100 \mu \mathrm{s}$, lasting $T=0,5 \mathrm{~s}$,

- normal: the first power surge $I=100 \mathrm{kA}, T_{1} / T_{2}=10 / 350 \mu \mathrm{s}$, lasting $T=0,5 \mathrm{~s}$.

The impact has a low energy $(\mathrm{kWh})$ of $0.001 \mathrm{~s}$ but produces a high voltage. Impulse current is $I>200 \mathrm{kA}$ with effects similar to high frequency currents. Impacts produce damage-fires, destruction, thermal (thermal) effects and mechanical effects (depending on the amplitude and duration of the input current.

Table 2. Maximum parameter values depending on the protection level and the degree of threat

\begin{tabular}{|c|c|c|c|c|c|}
\hline Size & Unit & Lightning current size & \multicolumn{3}{|c|}{ Protection level } \\
\hline \multicolumn{3}{|c|}{ The first current pulse } & I & II & III \\
\hline$I$ & $\mathrm{kA}$ & $\begin{array}{l}\text { Amplitude value of } \\
\text { current }\end{array}$ & 200 & 150 & 100 \\
\hline$T_{1} / T_{2}$ & $\mu \mathrm{s} / \mu \mathrm{s}$ & Values of time constants & $10 / 350$ & & \\
\hline \multicolumn{6}{|c|}{ Next impulse } \\
\hline$I$ & $\mathrm{kA}$ & $\begin{array}{l}\text { Amplitude value of } \\
\text { current }\end{array}$ & 50 & 37.5 & 25 \\
\hline$\Delta I / \Delta t$ & $\mathrm{kA} / \mu \mathrm{s}$ & $\begin{array}{l}\text { Mean value of the slope } \\
\text { of the current }\end{array}$ & 200 & 150 & 100 \\
\hline$T_{1} / T_{2}$ & $\mu \mathrm{s} / \mu \mathrm{s}$ & Values of time constants & $0.25 / 100$ & & \\
\hline$T_{\text {long }}$ & $\mathrm{s}$ & $\begin{array}{l}\text { The time constant of a } \\
\text { wave of longer duration }\end{array}$ & 0.5 & & \\
\hline
\end{tabular}

The protection of underground installations against discharge is carried out according to EN 62305-4 edition 2 [12]. In the geographical and climatic conditions of the Republic of Serbia, currents of 20-40kA may occur, and currents above 100kA only exceptionally. Waveforms characterize the first power surge. Value $I$ (A) from the Table 2 represents to us the amplitude value-the maximum value reached in the first part of the duration of atmospheric discharges (determines the maximum voltage drop at ground resistance, is important for the potential increase to earth. From this value, the maximum step voltage and contact near the shielded object is calculated), while $T$ (s) is the time atmospheric discharge duration-the time the lightning current passes through the impact site. $T_{1}$ is the time of front 
wave $(10 \mu \mathrm{s})$-the virtual parameter defined as 1.25 times the time since reaching $10 \%$ of the $90 \%$ current amplitude, $T_{2}$ is the time of the beginning of the wave $(350 \mu \mathrm{s})$-a parameter defined as the time from start to time when the current dropsup to $1 / 2$ amplitude value (an impuls).

At electrical systems in urban areas, the registered atmospheric discharges are:

- direct impact on an object (conduit representing a power source),

- indirect impact near the conduit (excessive currents and surges are transmitted to the grid).

The resultant value of the resistance in the soil is called the impact resistance of propagation [4]. For higher frequency atmospheric discharge resistance $R_{u}$ depends oncurrent-slope shape, $d i / d t=0,3-80 \mathrm{kA} / \mu \mathrm{s}$.

\section{Elements of Underground Installations, Earthings and Earthers}

Elements of underground installations (example of one urban electric transport, Fig. 1) are analyzed as parts of electric circuits with distributed: longitudinal $\left(r, l_{L}\right)$ parameters of elements in the power branch and transverse $(g, c)$ parameters of the element in the voltage branch $[9,16]$.

The main elements of underground installations analyzed in this paper, are metal pipes and in terms of compatibility with processes on cables, their important longitudinal parameters: resistance, inductance, capacitance and drainage.

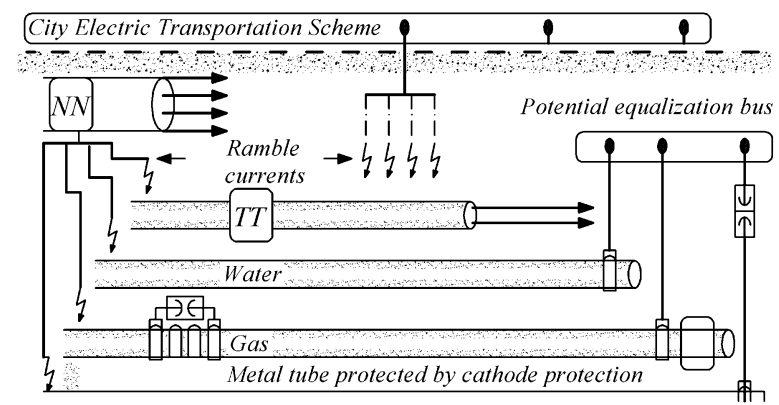

Fig. 1. Detail of underground installations

Wandering currents in the soil from 'foreign' electrical sources act as atmospheric discharge currents and around the ground create a strong field depending on the conductivity of the soil. The earth acts as a receiver; the electromagnetic wave encounters a change in impedance $Z_{1}$ on $Z_{2}$, Fig. 2. Voltage wave electricity ( $V_{1}$ in, $V_{2}$ passed) at points of discontinuity it will convert to magnetic energy (current wave), the amount of which depends on the ratio $Z_{1} / Z_{2}[11]$.

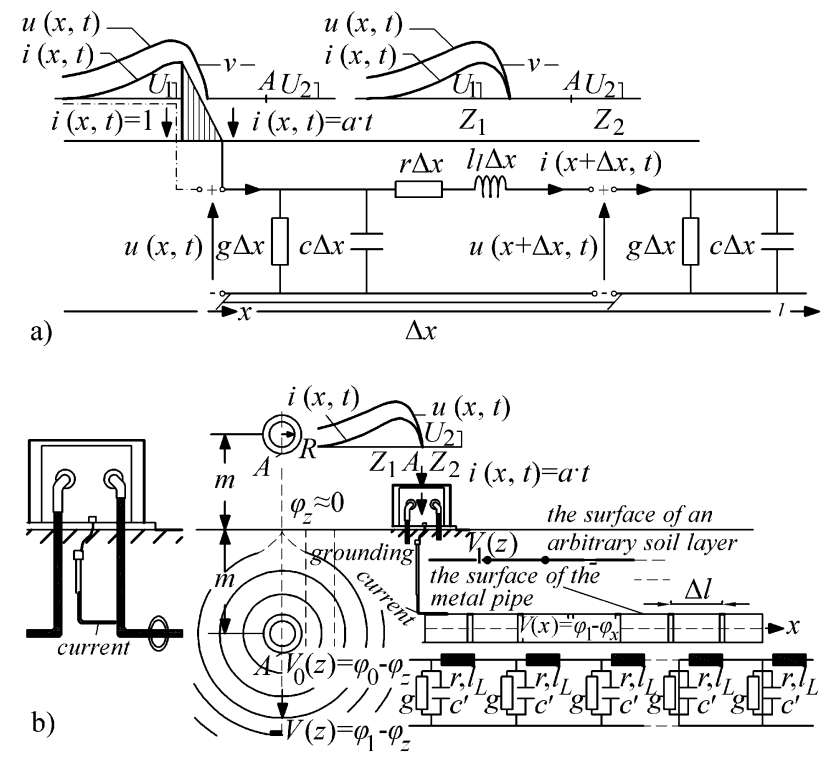

Fig. 2. Equivalent ground part scheme and current waveform with discontinuity $Z_{1}$ and $Z_{2}$ 
In this part of the paper we will not deal with the calculation of transient processes on electrically conductive metallic elements of an underground installation, but will only use the final products of the equations derived in [3].

The current and voltage at the grounding part (where the current enters the ground) are (final formulas) [3]:

$$
\begin{aligned}
& I(x)=I_{p} \operatorname{ch} \gamma x-\frac{U_{p}}{Z_{0}} \operatorname{sh} \gamma x \\
& U(x)=U_{p} \cdot \operatorname{ch} \gamma x-Z_{0} I_{p} \cdot \operatorname{sh} \gamma x
\end{aligned}
$$

The solutions define the parameters of the conduit pipe and the earth and they can be written in: a) complex and b) time domain:

for voltage:

$$
\begin{aligned}
& \text { a) } V=M e^{\beta \cdot x} e^{j\left(\omega t+\varphi_{1}+\alpha \cdot x\right)}+N e^{-\beta \cdot x} e^{j\left(\omega t+\varphi_{2}-\alpha \cdot x\right)} \\
& \text { b) } v(x, t)=\sqrt{2} M e^{\beta x} \cos \left(\omega t+\varphi_{1}+\alpha x\right)+ \\
& +N e^{-\beta x} \cos \left(\omega t+\varphi_{2}-\alpha t\right)
\end{aligned}
$$

for current:

$$
\begin{aligned}
& \text { a) } I=K_{1} e^{\beta \cdot x} e^{j\left(\omega t+\varphi_{1}+\alpha \cdot x\right)}+K_{2} e^{-\beta \cdot x} e^{j\left(\omega t+\varphi_{2}-\alpha \cdot x\right)} \\
& \text { b) } i(x, t)=\sqrt{2} K_{1} e^{\beta x} \cos \left(\omega t+\varphi_{1}+\alpha x\right)+ \\
& +K_{2} e^{-\beta x} \cos \left(\omega t+\varphi_{2}-\alpha t\right)
\end{aligned}
$$

The algorithm with solutions of voltage, equation (2) and current, equation (3) is entered in psbramblecurrent.mdl and psbramlegas.mdl [8].

The maximum impedance value is:

$$
z(0, t)=\left[\frac{v(0, t)}{i(0, t)}\right]=\left[\frac{1}{g \ell}\left(1+\frac{2 T_{1}}{\tau_{c}} \sum_{1}^{\infty} \frac{1}{k^{2}}\right)\right] .
$$

where:

$$
t=\tau_{c}, T_{1}=\frac{l_{L} \ell g \ell}{\pi^{2}}=\frac{l_{L} \ell^{2}}{\pi^{2}} \frac{1}{R}
$$

On Fig. 3 the time and voltage ground values are given with the wavefront and resistance values that were used for the elements of underground installations (an example of an urban electric transport).
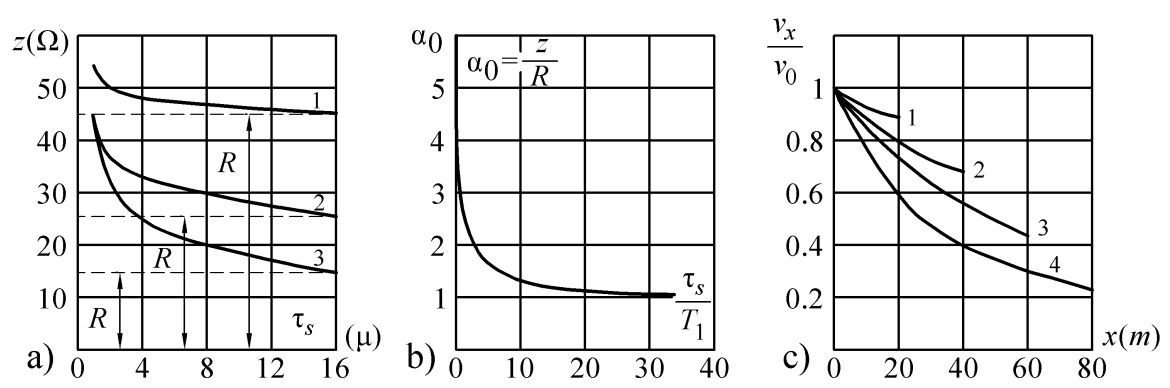

Fig. 3. a) Grounding impedance time: $t_{c} \approx \mu s$ in the soil, $\left.\left.\left.\rho=500 \Omega \mathrm{m}, \ell: 1\right) 120,2\right) 80,3\right) 40 \mathrm{~m}$, b) long-earthing impulse factor dependence $\left.\alpha_{0}=z / R=f\left(\tau_{c} / T_{1}\right), \mathrm{c}\right)$ voltage along ground: $t_{c}=3 \mu \mathrm{s}$ in the soil, $\left.\left.\left.\rho=500 \Omega \mathrm{m}, \ell: 1\right) 120,2\right) 80,3\right) 40 \mathrm{~m}$

Impulse impedance has 2 members: active-stationary $R=R_{\text {stat. }}$ resistance and complementary $R_{\text {comp. }}=\frac{L \ell}{3 \tau_{\check{c}}}$ resistance, Fig. 3.a, and it differs from the formula of grounding resistance, Table 3 (IEC 50364) [7]. 
The lasting of the process depends on $T_{1}$ :

$$
\alpha_{0}=\frac{z(0, t)}{R}=\left[1+\frac{T_{1} \pi^{2}}{3 \tau_{c}}\right]=\left[1+\frac{l_{l} \ell}{R 3 \tau_{c}}\right]=\left[1+\frac{1}{3 \tau_{c}} \frac{L}{R}\right]
$$

Active-stationary resistance is:

$$
R_{\text {stat. }}=r \ell=\frac{1}{\ell g}=\frac{1}{\ell} \frac{\varepsilon}{\sigma} \cdot \frac{1}{2 \pi \varepsilon} \ln \left[\frac{h}{2 r_{s}}+\sqrt{\left(\frac{h}{2 r_{s}}\right)^{2}-1}\right]
$$

The inductance-induced additional resistance depends on the relationship ( $\left.\tau_{c} / T_{1}\right)$ :

$$
R_{\text {comp. }}=R \frac{\pi^{2} T_{1}}{3 \tau_{c}}\left(1-\frac{6}{\pi^{2}} \sum_{k=1}^{k=n} e^{-\tau_{c} / T_{k}}\right)
$$

From the equation $L_{L}=R \frac{\pi^{2}}{3} \frac{T_{1}}{\tau_{\check{c}}}$ the effect of inductance is smaller the larger the ratio $\tau_{c} / T_{1}$ and less soil resistance $R_{\text {stat. }}$.

Inductance $l_{L}$, length $\ell$, diameter $d_{0}$ is calculated from the equation:

$$
l_{L}=0.2\left[\ln \frac{2 h}{d_{o}}-1\right] . \cdot\left[\frac{\mu H}{m}\right]
$$

If it grows $\tau_{c}$ and $R$, then $\alpha_{0}=\frac{z}{R} \rightarrow 1$. Then the effect of the inductance is smaller and the grounding conducts itself as elongated.

Inductance affects the resistance of grounding, voltage and current and must be taken into account in contrast to the previous norm JUS N.B4.800 for grounding in which the inductance parameter is neglected.

The diagram $z=f\left(\tau_{c}\right)$ on Fig. 3.a impendance $z \rightarrow R_{\text {stat. }}$, i.e. is smaller than grounding length.

Grounding length $l \leq 20 \mathrm{~m}$, during front lasting $\tau_{c}(\mu \mathrm{s})$ in the soil, resistance $\rho=500 \Omega \mathrm{m}$ acts as a concentrated vertical (type A) rather than a radial one [17].

On diagram Fig. 3.b gives is an impuls coefficient $\alpha_{0}$ long grounding of distributed parameters $\alpha_{0}=\frac{z}{R}=f\left(\frac{\tau_{c}}{T_{1}}\right)$. If $\left[\frac{1}{3 \tau_{c}} \frac{L}{R}\right]<0.1$ in $\alpha_{0}$, then $T_{1} \frac{\pi^{2}}{3 \tau_{c}} \leq 0.1 \Leftrightarrow \frac{\tau_{c}}{T_{1}} \geq \frac{\pi^{2}}{0.3} \approx 33$.

The diagram in Fig. 3.c shows the voltage along radial grounding of various lengthsand $t_{c}=3 \mu$ s, resistance $\rho=500 \Omega \mathrm{m}$. The voltage along radial grounding depends on the slope $a$ and current $i$.

The effect of supplemental resistance on active-stationary resistance need not be considered as for grounding with concentrated parameters. This fact has been introduced in both the IEC and SRPS standards.

Table 3 lists the types and types of grounding and grounding conductors used to protect against atmospheric discharges, according to IEC 50364 [7]. 
Table 3. Type and types of earthing and grounding conductors for protection against atmospheric discharges, by IEC 50364 [7]

\begin{tabular}{|c|c|c|c|c|c|}
\hline Shape and dimensions & Ground resistance $(\Omega)$ & Exact term & $\begin{array}{l}\text { Application } \\
\text { condition }\end{array}$ & $\begin{array}{c}\text { Approximate term } \\
(\Omega)\end{array}$ & Application condition \\
\hline$\sim$ & $R=\frac{\rho}{2 \cdot \pi \cdot l} \ln \frac{4 \cdot l}{d}$ & $R=0.9 \frac{l}{d}$ & $l>>\frac{d}{2}$ & $R=\frac{1}{\left[\frac{0.9 \eta}{R_{1}} n+\frac{1}{R_{0}}\right]}$ & $\begin{array}{l}\qquad l \gg \frac{d}{2} \\
\text { the situation } \\
l=1-3 \mathrm{~m}\end{array}$ \\
\hline $\begin{array}{l}\text { Striped or wired; width bar } b \\
d=b / 2, z=h\end{array}$ & $R=\frac{\rho}{2 \pi \cdot l}\left(\ln \frac{2 l}{d}+\ln \frac{l}{2 z}\right)$ & $z<<l / 4$ & $l \gg d$ & $R=2 \frac{\rho}{l}$ & $\begin{array}{l}\quad l \gg d \\
\text { the situation } \\
l=10-50 \mathrm{~m}\end{array}$ \\
\hline $\begin{array}{l}\text { Ring. ribbon or wire; width bar } \\
b: d=b / 2, z=h\end{array}$ & $\begin{array}{c}R=\frac{\rho}{2 \pi^{2} D}\left(\ln \frac{8 D}{d}+\ln \frac{l}{2 z}\right) \\
D \gg d\end{array}$ & & $z<<\frac{D}{2}$ & $R=2.1 \frac{\rho}{l}$ & $\frac{D}{z} \gg>10$ \\
\hline $\begin{array}{c}\text { Airy } \\
\text { ribbon/wired: } h=z<1\end{array}$ & $R=\frac{\rho}{4 \pi \cdot l}\left(\ln \frac{2 \cdot l}{d}+1\right)$ & $R=\frac{\rho}{4 \pi \cdot l}\left(\ln \frac{2 \cdot l}{d}+1\right)$ & $D \gg a$ & $R=2,1 \frac{\rho}{l}$ & $\begin{array}{l}l<30 \mathrm{~m} \\
l / 4>d\end{array}$ \\
\hline Mesh grounding & $R=\rho\left(\frac{1}{2 D}+\frac{1}{l}\right)$ & & & $R=\frac{\rho}{\pi D}$ & $\begin{array}{l}\text { Remark: For a grid of } \\
\text { flexible surface shape } \\
\qquad S: D=\sqrt{\frac{4 S}{\pi}}\end{array}$ \\
\hline
\end{tabular}

\section{Detection of Cable and Pipe Failures}

In the underground installation, 4 types of disturbances due to wandering currents are detected at length $l:$ earth fault, short circuit, interruptions and atmospheric discharges.

Classical methods are used for fault detection. Below we will list their most significant characteristics.

1. Method. For malfunctions in high resistance TT cables, wired methods are used and this: Wheastone bridge, Fig. 4.a, Heinzelmann method, Fig. 4.b and Muray method, Fig. 4.c.

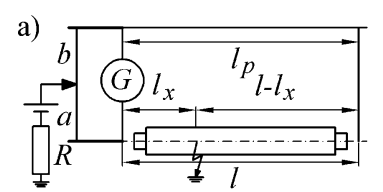

b)
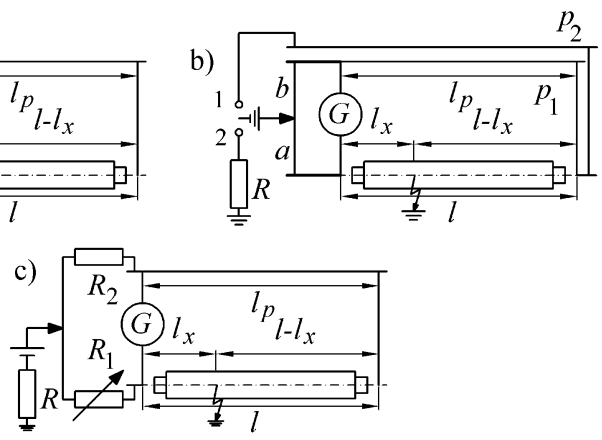

Fig. 4. a) Wheastone bridge, b) Heinzelman method, c) Muray method

2. Method. Return line measurements, Fig. 5.a, Measurements without return line, Fig. 5.b and detection ofshort circuit locations using a galvanometer, Fig. 5.c. The earth fault is detected by measuring the voltage drop. 
a)

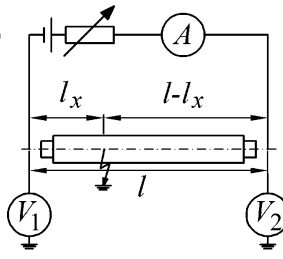

b)

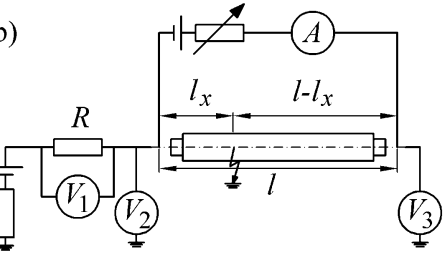

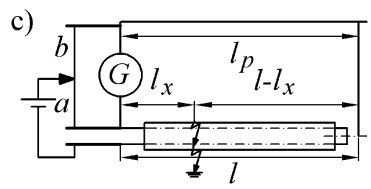

Fig. 5. Method: a) with return line, b) without return line, c) detection of short circuit location

3. Method. Modern standing wave method. At some generator frequency $30-10^{4} \mathrm{kHz}$ a standing wave is generated that is determined from the deflection of the voltmeter at the input $l_{x}=\frac{v n}{2 f_{1}}$. The frequency is then increased to obtain the maximum deflection on the voltmeter $l_{x}=\frac{v(n+1)}{2 f_{2}}$ and $l_{x}=\frac{v}{2\left(f_{2}-f_{1}\right)}=\frac{v}{2 \Delta f}$.

4. Method. A modern contactless method for detecting failure on a metal pipe of an underground installation, Fig. 6.a.

The wave also reaches the point of failure due to a change in impedance $Z_{1}$ and $Z_{2}$ a reflected wave is created. The fault location is determined by the method of electromagnetic amplitude and phase control (Radiodetection) [18].

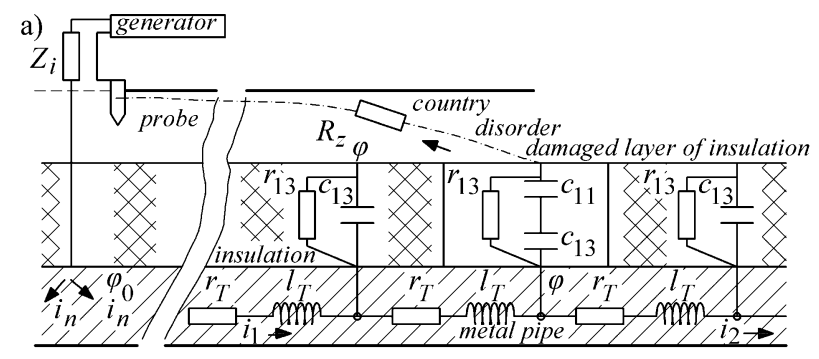

b)

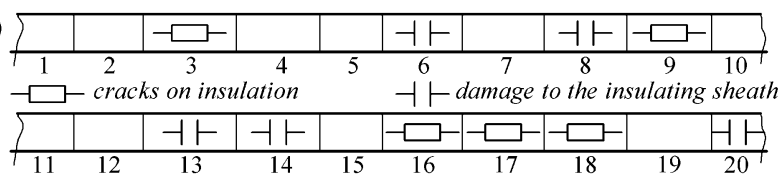

Fig. 6. a) Contactless method, control of electromagnetic waves, b) installation: diameter pipe analysis $d T=600 \mathrm{~mm}$ and length $l=20 \mathrm{~m}$ devided on 20 parts and possible malfunction on it (cracks and separated part of layer)

Phase current attitude, resistance and inductance at the break-in point of the insulated sheath of type "separate insulation" is the phase position of the current due to cracks is calculated from the formula calculated according to the form:

$$
\begin{gathered}
\varphi=2 \pi \cdot f \sqrt{\frac{r_{13} l_{T} c_{13} c_{I I}}{\left(Z_{i}+r_{T}+R_{Z}+r_{13}\right)\left(c_{13}+c_{I I}\right)}} . \\
r_{T}=\frac{1}{d_{T}} \sqrt{\frac{f \cdot \mu_{T} \cdot \rho_{T}}{\pi}}\left(\frac{\Omega}{m}\right) . \\
l_{T}=\frac{1}{\pi \cdot d_{T}} \sqrt{\frac{\mu_{T} \cdot \rho_{T}}{\pi \cdot f}}\left(\frac{\Omega}{m}\right) .
\end{gathered}
$$

where:

$Z_{i}$ generator impedance $\left(Z_{i} \approx 50 \Omega\right), R_{T}$ and $L_{T}$ tube resistance and inductance, $R_{Z}$ earth resilience 
( $R_{Z} \cong 10^{-7} \pi^{2} f$ ), $r_{13}$ and $c_{13}$ longitudinal parameters of resistance and capacitance, $c_{I I}$ capacitance of the damaged part of the sheath insulation (double layer), $f$ frequency, $d_{T}$ diameter, $\mu_{T}$ magnet conductivity, $\rho_{T}$ specific resistance.

In our case (an example of one city electric transportation), an analysis of pipe parameters is required: $r_{13}, c_{13}$ and separated cover $c_{I I}$ on the spot of damage, Fig. 6.a. The resistance and capacitance in the current field between conductive structures in the middle of low conductivity is:

$$
\begin{gathered}
r_{13}=1.2 \frac{\rho_{13}}{2 \pi} \ln \left(\frac{d_{T}+2 \delta_{13}}{d_{T}}\right) . \\
c_{13}=\frac{2 \pi \varepsilon_{0} \varepsilon \cdot l}{\ln \left(\left(d_{T}+2 \delta_{13}\right) / d_{T}\right)} .
\end{gathered}
$$

where:

$\delta_{13}$ thickness of insulation, $\varepsilon$ dielectric conductivity of the cover, $\varepsilon_{0}=8.85 \cdot 10^{-12} \mathrm{~F} / \mathrm{m}, l$ pipe length.

The capacity of a part of cover corresponds to the capacitor:

$$
c_{I I}=\frac{\varepsilon_{0} \varepsilon \cdot S}{d} .
$$

where:

$\varepsilon$ dielectric conductivity of the mid-tube-cover, $S$ the surface of the separated part of the cover, $d$ the distance from the surface of the metal pipe to the layer of insulating sheath.

The phase position of the current due to cracks is calculated from the formula:

$$
\varphi_{\text {crack }}=2 \pi \cdot f \sqrt{\frac{r_{I I} l_{T} c_{I I}}{Z_{i}+r_{T}+R_{Z}+R_{E}+r_{I I}}} .
$$

All these parameters depend on the diameter and operating frequency of the generator.

\section{Simulation Models and Results}

Analytical considerations performed show the functional capabilities of models with different frequencies.

Preparation of computer programs in the method of organized modeling is referred to in the technical literature as preprocessing (formation of technical system models). The system of previously derived equations is easily implemented into blocks provided by the software packageMATLAB Simulink [8]. The simulation program was implemented according to the scheme given in Fig. 7 and Fig. 8 in the new subprogram "psbramblecurrent.mdl and psbramlegas.mdl”.

Scheme desc: In the schemes of Fig. 7 and Fig. 8, a model algorithm was developed to control the condition and failures of underground electrical installations (line-SCOPY1, Breaker-SCOPY2, Load-SCOPY3). There is a penetration of wandering currents from foreign grounding on a part of the cable network and in the gas installation.

An adapted program was used to verify the model and algorithm MATLAB Simulink [8] and scheme on Fig. 7 with following parameters: penetration of the wandering current $33 \mathrm{kA}$ and $f=50 \mathrm{~Hz}$ into a single-core cable XHE $\mathrm{Al}$ $12 \mathrm{kV}, 95 \mathrm{~mm}^{2}$ laid in soil of specific resistance $\rho=100 \Omega \mathrm{m}$. The longitudinal parameters are: $r=0.2755 \Omega / \mathrm{km}$, $x=0.1 \Omega / \mathrm{km},(L=0.3 e-3 \mathrm{H} / \mathrm{km}, C=12.37 e-8 \mathrm{~F} / \mathrm{km})$.

The simulation scheme of Fig. 8 contains the following parameters: lightning current amplitude penetration from ground $33 \mathrm{kA}$ and $f=25 \mathrm{kHz}$ into a circular gas pipe $D_{2} / D_{1}=33 / 31 \mathrm{~mm}$ laid in soil of specific resistance $\rho=100$ $\Omega \mathrm{m}$, approximately the same equivalent electrical parameters: $r=0.2755 \Omega / \mathrm{km}, x=0.1 \Omega / \mathrm{km},(L=0.31 e-3 \mathrm{H} / \mathrm{km}$, $C=12.37 e-8 \mathrm{~F} / \mathrm{km}$.

Fig. 9 and Fig. 10 simulation diagrams of wandering currents and voltages are given.

Simulation: In the case of atmospheric discharges, the potentials are $V \approx(1-10) \mathrm{MV}$, but the polarity of the voltage is controversial. Negative strokes reach the ground at one point through the leader and are stronger than positive strokes that travel across branches of streamers that carry only part of the charge.

The program contains a fast Fourier transform, FFT and an algorithm for the calculation of transient processes for atmospheric discharge simulated by a high-amplitude and frequency current source and a ground current from another 
network-10kV and frequences-50Hz. For the simulation, an example of a power source equivalent to a negative impact originating from ground-to-ground was taken.

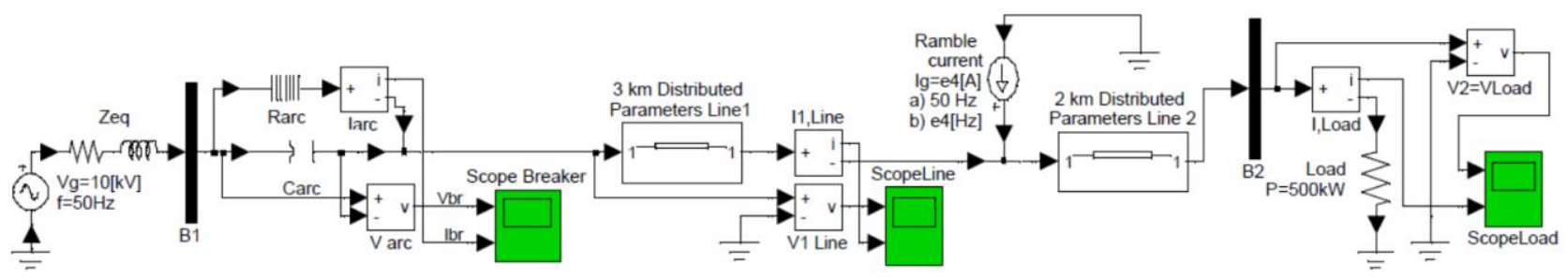

Fig. 7. Wandering current on the part of the cable network: at the switch, inlet to the line $L_{1}$ and burden $L_{2}$

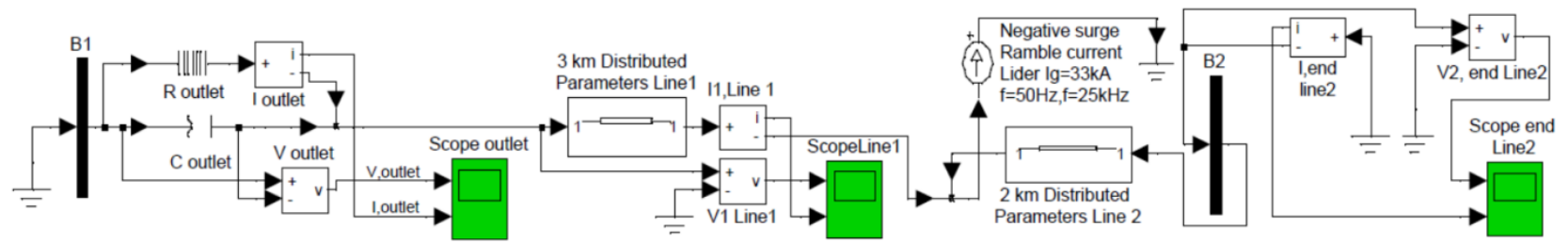

Fig. 8. The penetration of wandering current into the gas installation

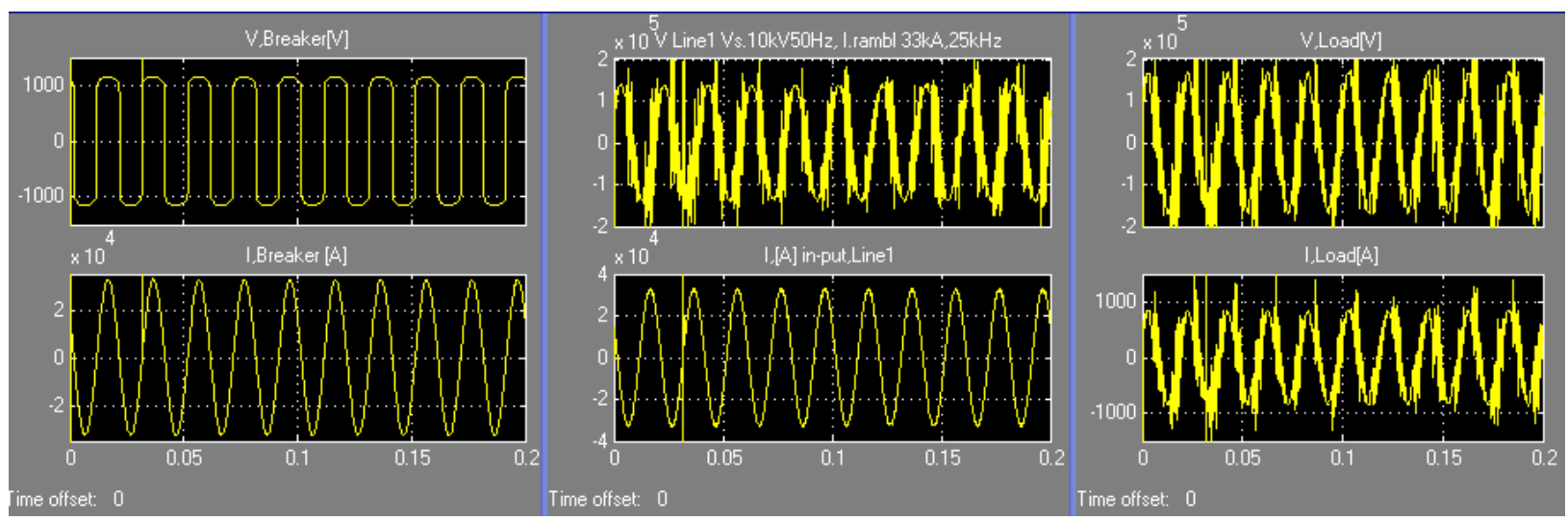

Fig. 9. Measured voltage and current diagrams on a part of a cable network

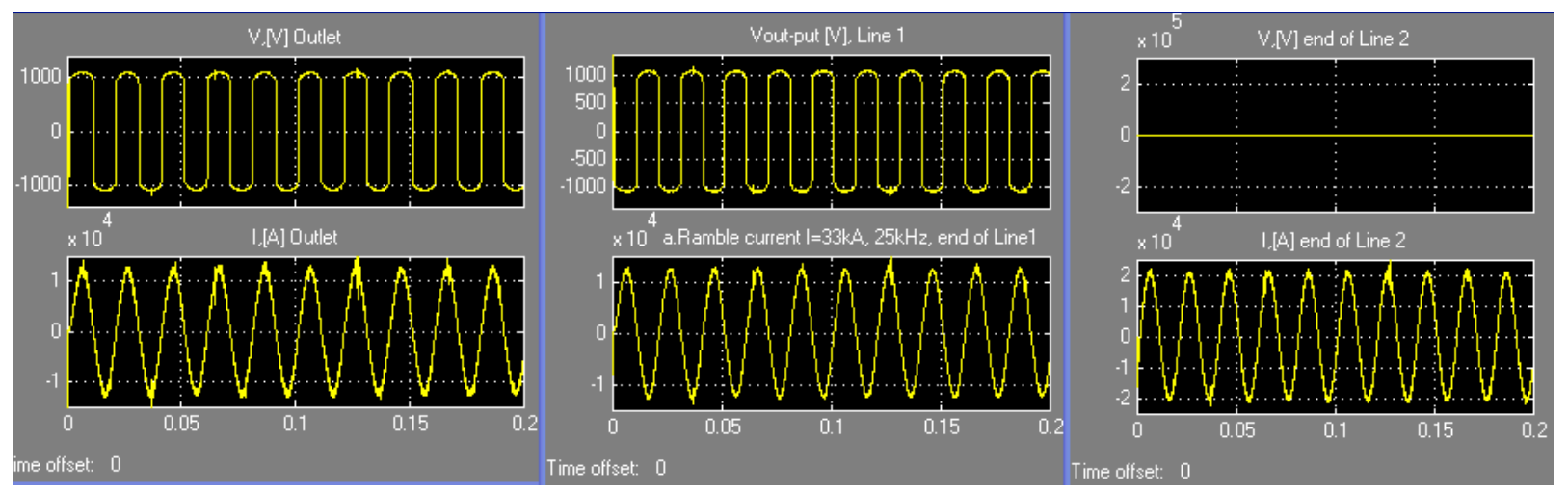

Fig. 10. Measured voltage and current diagrams on the part of the gas installation

The analysis of current and voltage diagrams indicates a much greater influence of stray currents in electrical cable installations with metal sheaths in terms of the appearance of higher harmonics, compared to underground gas installations with metal pipes. The reason for this increased influence are different values of $r, l, c, g$ parameters of these two underground installation.

The advantages of MATLAB are the large number of possible simulations, and the results of these simulations, the shapes and characteristic values of the resulting wave diagrams, verify the proposed method for considering transient processes on underground installation elements. 
Finished MATLAB Simulink programs accurately simulate elements of underground installations, but their own development of both models and programs has special advantages, such as a detailed insight into all components of the model and program and making various changes that would not otherwise be possible in the available software packages.

\section{Conclusion}

Classical methods are semi-empirical and without algorithms that precede artificial intelligence methods: validated simulations and graphical tests: AI-artificial intelligence method-simulated annealing, graph search. Simulation methods can be applied in the control of conditions and faults in the isolation of underground installations as well as voltages and currents along the conductive structure of installations since experimental methods are not always possible.

The analytical procedure and formulas similar to those obtained at higher frequencies serve to evaluate the influence of the parameters on the level of electric shock. In the design of underground installations with metal pipes, innovative methods and simulations also show the possible effects of soil parameters and elements of the underground installation on the processes of extreme wandering currents. Electrical break through in the soil is influenced by high voltage values $10^{6} \mathrm{kV}$ which produce these extreme currents of order up to $10^{5} \mathrm{kA}$.

In the design and implementation of underground installations with metal pipes in urban areas, and with respect to criteria of environmental protection and experience, more perfect knowledge can be acquired than those acquired in education. That is why mathematical procedures are innovated and simulations are introduced that show possible influences of soil parameters and elements of underground installation on transient processes. The formulas obtained in this paper can be used to assess the influence of all relevant parameters on the character of transient process when creating stray currents.

\section{References}

[1] Z. Bogićević, S. Bjelić, B. Jovanović, M. Mišić, "Neutral grounding points within the general distribution system as an element of environmental protection", pp. 779-787, $3^{\text {rd }}$ International Academic Conference, Places and Technologies, Belgrade, Serbia, 14.-15.04.2016.

[2] L. Van der Sluis, W.R. Rutgers, C.G.A. Koreman, "A physical arc model for the simulation of current zero behaviour of highvoltage circuit breakers", IEEE Transactions on Power Delivery, pp. 1016-1022, Vol. 7, Issue 2, Apr. 1992, DOI: $10.1109 / 61.127112$.

[3] Bojan L. Jovanović, Slobodan N. Bjelić, Nenad A. Marković, "Transient Processes on the Elements of Underground Installations", International Journal of Information Technology and Computer Science(IJITCS), Vol.9, No.9, pp.1-10, 2017. DOI: $10.5815 /$ ijitcs.2017.09.01.

[4] N. Marković, S. Bjelić, U. Jakšić, Z. Bogićević, "Graphical Zero-sequence Cut-offs Method of Determining of Fault to Earth in Electrical Lines", 9th Symposium on Neural Network Applications in Electrical Engineering, Faculty of Electrical Engineering, University of Belgrade, Serbia, Neurel 2008, pp. 73-76.

[5] Nenad Marković, Slobodan Bjelić, Jeroslav Živanić, Zorica Bogićević,"Analysis and Estimation of Values of Currents and Voltages at the Disturbances in Induction Machine Using Tested Matlab Simulation", International Journal of Intelligent Systems and Applications(IJISA), vol.7, no.1, pp.1-8, 2015. DOI: 10.5815/ijisa.2015.01.01.

[6] S. Bjelić, "Protection Techniques in Electrical Energy Networks", pp. 117-118, 2018.

[7] Standards: EN 50162, IEC 50364, IEC 50364, IEC 60364-5-54-2012/A11, EN 62561-2-013.

[8] MATLAB SIMULINK Sim Power System, Copyright 1984-2002 The Math Works, Version 6.5.0,180913a, June 2, 2000.

[9] J. Surutka, "Electromagnetics," Building book, University of Belgrade, pp. 231-232, 378-386, 1966.

[10] B. Ilić, B. Savić, "Influence of stray currents to information and comunication technology" Technical School Center, InfotehJahorina, Vol. 9, Ref. D-13, March 2010, pp. 413-417.

[11] M. Tanasković, T. Bojković, D. Perić, “Distribution of electric energy,” Academic Thought, Belgrade, pp. 48-70, 2010.

[12] Standards: IEC 62305-1, EN 62305-4.

[13] C. Magono, "Thunderstorms", Elsevier Scientific Publishing Company, 335 Jan van Galenstraat, Amsterdam, The Netherlands. 1980.

[14] S. Bjelić, B. Jovanović, Z. Bogićević, N. Marković, I. Bjelić, "Theoretical Model of the Electric Field of Stray Currents in Underground Installations in Urban Environments", Bjast 2017, Review Article, Vol. 19, Issue 4, 2017/BJAST/31690.

[15] N. Marković, S. Bjelić, "Protection against dangerous effects electric current", Kvark, Kraljevo, pp. 153-192, 2018.

[16] L. Van der Sluis, W.R. Rutgers, C.G.A. Koreman, "A physical arc model for the simulation of current zero behaviour of highvoltage circuit breakers", IEEE Transactions on Power Delivery, pp. 1016-1022, Vol. 7, Issue 2, Apr. 1992, DOI: $10.1109 / 61.127112$.

[17] PC EPS Directorate for Electricity Distribution of Serbia, Belgrade, “Technical Recommendation no. 7,” III edition, jun 1996.

[18] A.V. Permyakov, R.M. Sultanov, F.Sh. Khafizov, I.F. Khafizov, L.A. Sakeyan, "Electrical solution of the dielectric and its influence on flame emission with electromagnetic field," Сетевое издание «Нефтегазовое дело», 2-2018, pp. 117-128, UDK 614.841 . 


\section{Authors' Profiles}

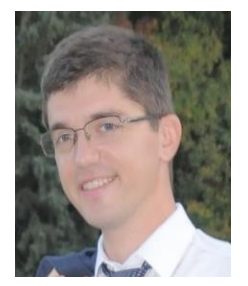

Igor S. Bjelić: His doctoral dissertation teses was: "Typology and structural characteristics of arches and vaults of sacral buildings in the medieval Serbia", Faculty of Civil Engineering and Architecture, University in Nis, September 2016. He is author and over 40 scientific and professional papers published in international and Serbian journals.

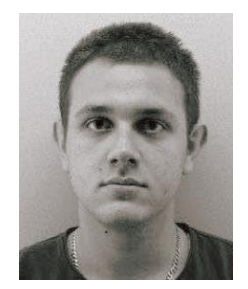

Filip N. Marković: Student on 3rd year at Faculty of Technical Sciences-University in Pristina with temporarily seat in Kosovska Mitrovica. Field of interest: Electrical and Computer Engineering, Computer Engineering and Software Engineering. He is author and co-author of several papers in the field of electrical engineering and computer science published in national and international peer-reviewed journals.

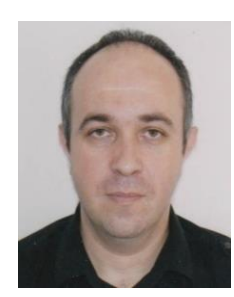

Nenad A. Marković: Professor at study programs Mechanical engineering and Road Traffic on High Technical School of Professional Studies Urosevac with temporarily seat in Leposavic. He is received his Ph.D. degree from Faculty of technical Sciences in Cacak-University of Kragujevac. Author and co-author is of many textbooks, exercises and over 120 papers published in international and Serbian journals.

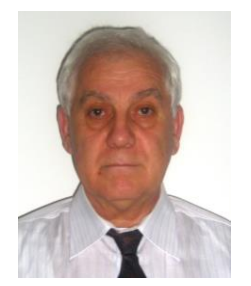

Slobodan N. Bjelić: Full-time professor at Faculty of Technical Sciences University in Pristina with temporarily seat seat in Kosovska Mitrovica. He received his Ph.D. degree in 1982, field of interest: Electrical EngineeringComputer Science-Protective Relays-Electrical Installation and Illumination Engineerings-Electrical Power Converters. He is author and co-author of 10 textbooks and over 200 scientific and professional papers published in international and Serbian journals.

How to cite this paper: Igor S. Bjelić, Filip N. Marković, Nenad A. Marković, Slobodan N. Bjelić, " Influence of Metal Pipes in the Environment on Designing the Underground Electrical Installations", International Journal of Image, Graphics and Signal Processing(IJIGSP), Vol.12, No.6, pp. 1-12, 2020.DOI: 10.5815/ijigsp.2020.06.01 